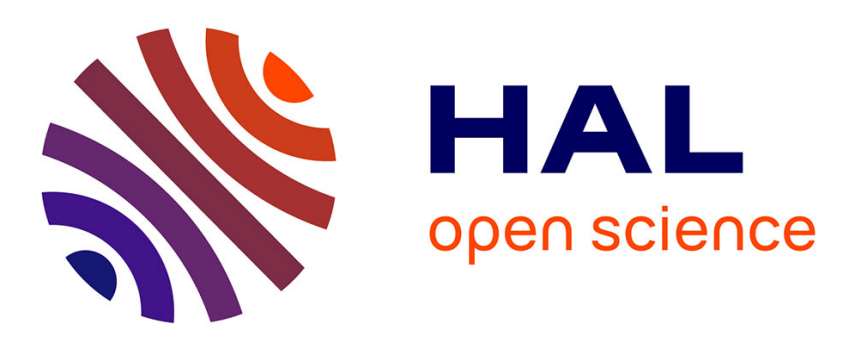

\title{
CHEMICAL OXYGEN-IODINE LASER IN PERIODICALLY-PULSED REGIME OF GENERATION
}

J. Schmiedberger, J. Kodymová, J. Ková[math], O. [math]palek, P. Trenda

\section{- To cite this version:}

J. Schmiedberger, J. Kodymová, J. Ková[math], O. [math]palek, P. Trenda. CHEMICAL OXYGENIODINE LASER IN PERIODICALLY-PULSED REGIME OF GENERATION. Journal de Physique IV Proceedings, 1991, 01 (C7), pp.C7-629-C7-632. 10.1051/jp4:19917169 . jpa-00250846

\section{HAL Id: jpa-00250846 https://hal.science/jpa-00250846}

Submitted on 1 Jan 1991

HAL is a multi-disciplinary open access archive for the deposit and dissemination of scientific research documents, whether they are published or not. The documents may come from teaching and research institutions in France or abroad, or from public or private research centers.
L'archive ouverte pluridisciplinaire HAL, est destinée au dépôt et à la diffusion de documents scientifiques de niveau recherche, publiés ou non, émanant des établissements d'enseignement et de recherche français ou étrangers, des laboratoires publics ou privés. 


\title{
CHEMICAL OXYGEN-IODINE LASER IN PERIODICALLY-PULSED REGIME OF GENERATION
}

\author{
J. SCHMIEDBERGER, J. KODYMOVÁ, J. KOVÁŘ, O. ŠPALEK* and P. TRENDA \\ Institute of Physics, Czechoslovak Academy of Sciences, Na Slovance 2, 18040 Prague 8, \\ Czechoslovakia \\ *Institute of Inorganic Chemistry, Czechaslovak Academy of Sciences, Máchova 24, \\ 16000 Prague 6, Czechoslovakia
}

\begin{abstract}
A periodically-pulsed regime of generation in an originaliy CW chemical oxygen-iodine laser (CoIL) using magnetic modulation of gain is presented. An experimental verification of feasibility of a direct magnetic gain switching in the active zone of COIL utilizing the zeeman effect is demonstrated.
\end{abstract}

1. Introduction

A Chemical Oxygen-Iodine Laser (CoIL) can generate kilowatt output powers in the CW regime of laser generation on the $1.315 \mathrm{\mu m}$ wavelength $/ 1 /$. The lasing mechanism is based on the energy transfer from metastable molecular oxygen in the delta state $O_{2}\left({ }^{2} \Delta_{g}\right)$ to the atomic lodine $I\left({ }^{2} P_{3 / 2}\right)$ after $I_{2}$ collisional dissociation by singlet oxygen. There are three experimentally verified schemes of how to operate COIL in a pulsed regime of generation. One of them $/ 2 /$ comes from the combined chemical pumping and the flashlamp photodissociation of perfluoralkyliodides producing atomic iodine in a pulsed way. Another technique $/ 3 /$ combines the chemical pumping with the pulsed electric discharge used for an electron initiation of atomic lodine production. These two methods are not applicable in a COIL in which atomic lodine is produced from molecular iodine. The third method used for the COIL system is a Q-switching technique of either the mechanical /4/ or magnetooptical /5/ type. Typical properties of a COIL - low gain, low output coupling, and near threshold generation cause the Q-switching of generation $/ 4,5 /$ to lead to a substantial increase in intraresonator losses. This lowers the mean value of the output power in comparison to the $\mathrm{CW}$ regime. The usual construction of a COIL has internal mirrors purged by inert gas, with a pressure difference between the inner and outer sides of mirrors aprox. 100 $\mathrm{kPa}$; thus, e.g., modulation of their position as the further method of pulsing would also be problematic. Pulse injection techniques or pulsing the chemical pumping do not seem to be suitable methods for this purpose as well.

2. Theoretical background

The principle of the method we present here is based on a direct magnetic modulation of gain in the active zone of a coIL utilizing the Zeeman effect on the laser transition ${ }^{2} \mathrm{P}_{1 / 2}-{ }^{2} \mathrm{P}_{3 / 2}$ of iodine atoms. An increase in the magnetic field in the range $0-500 \mathrm{G}$ causes $a$ 
significant monotonous decrease in the gain coefficient on the strongest transition 3-4 of hyperfine structure of laser transition ${ }_{P_{1 / 2}}-{ }_{P_{3 / 2}}$ at low pressure of the active medium $/ 6 /$. Our method does not cause an increase in intraresonator losses as with the above mentioned Q-switching technique. It means that the same level of the mean power in the $\mathrm{CW}$ and pulsed regime can be maintained. The relatively low values of magnetic field are sufficient, together with an absence of a substantial pressure broadening of the laser transition to obey an (under)threshold condition (1a) and to quench the laser generation:

$$
\frac{2 \alpha_{34}(B) 1}{\delta_{0}+\delta_{0}}\left\{\begin{array}{l}
\leq 1 \\
>1
\end{array}\right.
$$

where $\alpha_{34}(B)$ is the small-signal gain caused by the zeeman effect at magnetic field $B, 1$ is the active zone length, $\delta$ are the intraresonator losses and $\delta_{\theta}$ is the output coupling of the resonator $\left(\delta_{2}=\delta_{1}+\delta_{2}\right.$ where $\delta_{1}$ and $\delta_{2}$ are transmissions of resonator mirrors). The above-threshold condition (1b) is valid for the cases with an absence or presence of a weak magnetic field in the active zone (i.e. $0 \leq B_{t h} B^{\prime}$. The unsaturated small-signal gain on the laser transition 3-4 means $\alpha_{34}(B=0)$, and the threshold gain $\alpha_{34}\left(B_{t h}\right.$ ) obeys the equality in (1a). The upper limit of magnetic field induction - approximately $500 \mathrm{G}-$ is given by equalising the gain coefficients on $3-4$ and $2-2$ transitions in the hyperfine structure of $a{ }^{2} p_{1 / 2}-{ }^{2} P_{3 / 2}$ laser transition $/ 7 /$.

The quenching of the laser generation obeying the (under) threshold condition ( $1 a$ ) is the first step in obtaining a pulse generation of a CoIL. After keeping the laser without generation for a time interval necessary to exchange the laser gas mixture in the active zone (usually of the order of $10^{-3} \mathrm{~s}$ ), the magnetic field is quickly switched off, the laser gain reaches its "natural" value, and a laser pulse is generated. Repeating this cycle yields to a repetitively pulsed operation of a COIL with repetition rates of the order of $1 \mathrm{kHz}$. The principle of this method is the magnetic switching between the (under)threshold and the "natural" unsaturated above-threshold gain levels in the coIL active zone. The optimal repetition rate is achieved if the time interval between two subsequent pulses is equal to the time necessary to exchange the gas in the active zone. The energy of a single pulse is determined by the CW output power and the repetition rate. The pulse length and the pulse power also depend on the rate of switching off the magnetic field, i.e., on the fall time of a magnetic pulse used for the modulation.

3. Experimental setup and observations

We performed a set of experiments to verify the above-mentioned proposal. The source of the external magnetic field was added to the usual scheme of the active zone of a COIL (see Fig. 1). It was formed by two rectangular coils, which were closely attached to the Plexiglas body of the laser. The average width of each coil was $19 \mathrm{~cm}$, the same as the mutual mean distance of both coils, thus ensuring a 


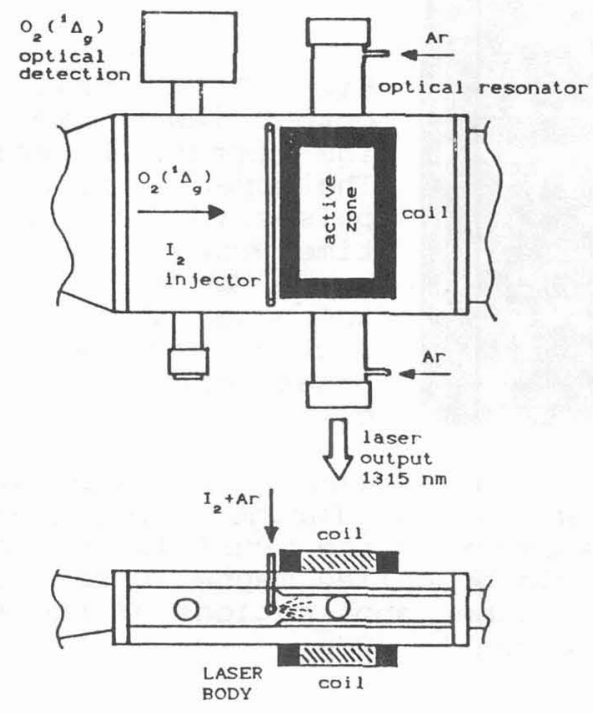

Fig. 1 Scheme of the experimental setup of the coIl active zone for measuring the magnetic gain modulation.

quasi-Helmholtz geometry in the transverse profile of the active zone of a COIL. In this case a homogeneous profile of a magnetic field in a plane perpendicular to the optical axis of the resonator was achieved. This ensures an unchanged transverse mode structure. The average length of the coil along the optical axis was $33 \mathrm{~cm}$. The length of the active zone was $40 \mathrm{~cm}$. Therefore, a magnetic field of sufficient value was produced, namely, in the central region of the active zone. Each coil had 20 turns of a rectangular copper conductor (cross section of $\left.100 \mathrm{~mm}^{2}\right)$. The coils had an inductance of $120 \mu \mathrm{H}$. They were performed in a parallel connexion with a pulse feeding in the range 0-250 A. The response of the magnetic field in the centre of the active zone was $0.4 \mathrm{G} / \mathrm{A}$. This parameter decreased parabolically in both directions with the distance from the centre of the active region. The magnetic field intensity at the ends of the active region was $28 \%$ of the central value.

The best results were obtained at the repetition rate $1560 \mathrm{~Hz}$, corresponding to a $0.64 \mathrm{~ms}$ period of pulsing and to a calculated gas flow velocity of $58 \mathrm{~m} / \mathrm{s}$. The rate of change of the magnetic field was $0.5 \mathrm{G} / \mu \mathrm{s}$. Under these conditions, a repetitively pulsed regime of generation in a COIL was obtained. A representative oscillogram of this operation can be seen in Fig. 2. The single-pulse length was 200 $\mu s$, and the pulse power to the $C W$ power ratio was 3.2 . The latter ( 15 W) had the same value both in the repetitively pulsed operation and in the CW regime of generation. The pulse power reached the value $48 w$. The value 3.2 of the ratio following from our experiments is very far from the theoretical limit (770) presented in $/ 8 /$ for $Q$-switching. The maximum experimental values are $11 / 4 /$ and $16 / 5 /$, both for Q-switching in CoIL. However, the mean value of power in these works was lowered during the repetitively pulsed operation by at least of 25 $\%$ compared to the CW regime. This is not our case. Our relatively low 


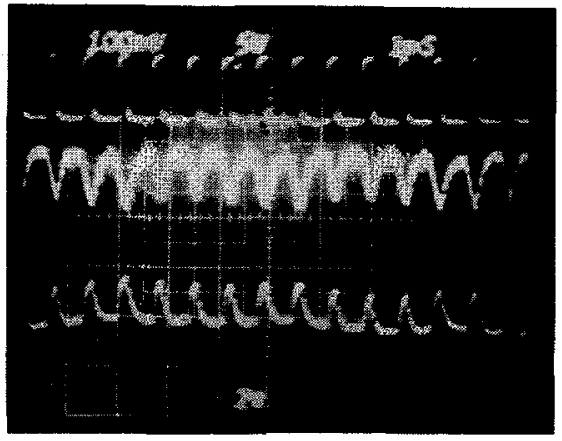

Fig. 2 Temporal dependence of the output laser power (lower trace) and the current in coils (middle trace). The upper trace belongs to the control pulses for the coil power supply. The time scale was $1 \mathrm{~ms} / \mathrm{div}$, the pulse power $48 \mathrm{~W}$, and the peak current of the power supply $250 \mathrm{~A}$. The modulation factors were $90 \%$ and $100 \%$ in the cases of current and output laser power, respectively.

experimental value can be increased by a higher rate of switching off the magnetic field and by a further optimization of the whole experiment. In the framework of the usual laser terminology, the above described technique could be called magnetic gain switching of a CoIL. Some proposals for other applications of the magnetic modulation of gain in a COIL are given in $/ 9 /$.

\section{Conclusion}

The magnetic gain switching in a COIL seems to be an advantageous and promissing method for pulsing the output power of this laser, and together with the high-power potential of oxygen-iodine active medium, may yield a practical use of this laser $/ 9 /$.

\section{References}

1/ S. Yoshida, H. Fujii, S. Amano, M. Endoh, T. Sawano, T. Fujioka, Seventh International Symposium on Gas Flow and Chemical Lasers, Proceeding Series P, SPIE Volume 1031, pp. 282-286, Vienna, 22-26 August 1988.

/2/ N.G. Basov, N.P. Vagin, P.G. Kryukov, D.Kh. Nurligareev, V.S. Pazyuk, N.N. Yuryshev, Kvantovaja elektronika, 11, No 10, pp. $1893-1894,1984$.

/3/ R. Zhang, F. Chen, X. Song, Q. Xu, C. Huan, Q. Zhuang, C. Zhang, Seventh International Symposium on Gas Flow and Chemical Lasers, Proceeding Series P, SPIE Volume 1031, PP. 308-311, Vienna, 22-26 August 1988.

/4/ F. Matsuzaka, T. Ohga, M. Imachi, T. Uchyiama, Proceedings of the 12th International Conference on Lasers and Applications, New Orleans, USA, pp. 223-227, December 3-8, 1989.

/5/ R. Highland, P. Crowell, G. Hager, Proceedings of the 12th International Conference on Lasers and Applications, New orleans, USA, pp. 228-236, December 3-8, 1989.

$16 /$ V.M. Kiselev, A.S. Grenishin, T.N. Kotlikova, L.I. Rodina, Kvantovaja elektronika, 11, No 8, pp. 1542-1554, 1984.

/7/ B.L. Borovich, V.S. Zujev, V.A. Katulin, L.D. Michejev, F.A. Nikolajev, O.Ju. Nosach, V.B. Rozanov, ITOGI NAUKI I TECHNIKI, RADIOTECHNIKA, Tom 15, Moskva, pp. 133-254, 1978.

18/ N.G. Basov, P.G. Kryukov, N.N. Yuryshev, Kvantovaja elektronika, 14, No 5, pp. 924-935, 1987.

/9/ J. Schmiedberger, J. Kodymová, J. Kovár̆, O. Spalek, P. Trenda, IEEE Journal of Quantum Electronics, Vol. 27, No. 6, June 1991, in press. 